\title{
The effect of education on the anxiety of a family with a patient in critical care unit: a systematic review and meta-analysis
}

Vida Shafipour ${ }^{1}$, Mahmood Moosazadeh ${ }^{2}$, Yadollah Jannati ${ }^{3}$, Fariba Shoushi ${ }^{4}$

${ }^{1}$ Ph.D., Assistant Professor, Department of Medical-Surgical Nursing, Nasibeh Nursing \& Midwifery Faculty, Mazandaran University of Medical Sciences, Sari, Iran

${ }^{2}$ Ph.D., Assistant Professor, Health Sciences Research Center, Faculty of Health, Mazandaran University of Medical Sciences, Sari, Iran

${ }^{3} \mathrm{Ph} . \mathrm{D}$., Assistant Professor, Psychiatry and Behavioral Sciences Research Center, Addiction Institute, Mazandaran University of Medical Sciences, Sari, Iran

${ }^{4}$ MSc student of Nursing and Midwifery Faculty \& Student's Research Committee, Mazandaran University of Medical Sciences, Sari, Iran

Type of article: Meta-analysis

\begin{abstract}
Background: Studies have shown that family members of patients in intensive care units experience high levels of anxiety. Contradictions in the results of the studies conducted regarding the effect of training on the anxiety level of such families, emphasize the necessity of employing other research methods to eliminate these ambiguities.

Objective: This study applied meta-analysis to determine the effect of training on the anxiety level of families with patients in the intensive care unit.

Methods: In order to find electronically published studies from 1990 to 2016, the articles published in journals indexed in the following databases were used: Elsevier, Scopus, ProQuest, ISI, Web of Science, PubMed, Google scholar and Cochrane. For data analysis Stata Software version 11 was used and the heterogeneity index of studies was determined through Cochran (Q) and $\mathrm{I}^{2}$. Due to the heterogeneity, the random effect model was used to estimate the difference between the standardized mean of anxiety.

Results: In this meta-analysis and systematic review article, eight articles were found to be eligible. The number of samples in the initial studies into a meta-analysis included 387 patients in the intervention group and 393 people in the control group. Standardized difference of the mean anxiety score in the intervention group was 0.329 (CI 95\%: -0.756-0.099) units less than that of the control group, indicating that this effect was not statistically significant.

Conclusions: The results of this meta-analysis show that training will decline the anxiety level of a family with patients hospitalized in the intensive care unit, although the impact is not considerable.
\end{abstract}

Keywords: Family, Anxiety, ICU, Education

\section{Introduction}

A family is of the basis of physical, cultural, spiritual and psychosocial health of its members (1). However, there are factors that can suddenly affect the family's health (2). One of these factors can be the hospitalization of the one of the family members, which can create anxiety and psychological problems for others, particularly, if the patient is admitted into a stressful unit such as the intensive care unit (3-5). Hence, paying attention to patients' families is an important issue because the family often has the responsibility to protect the patient (3). The results of studies worldwide, demonstrate that family members of patients in intensive care units experience high levels of anxiety (58). The results of a study conducted in France showed that 49.3 percent of the family members of patients in

\section{Corresponding author:}

Fariba Shoushi, MSc student of Nursing and Midwifery faculty \& Student's Research Committee, Mazandaran University of Medical Sciences, Sari, Iran. Tel: +98.9113238133, Email: r.shoushi@gmail.com

Received: September 06, 2016, Accepted: February 06, 2017, Published: March 2017 iThenticate screening: January 28, 2017, English editing: February 14, 2016, Quality control: March 07, 2017 (C) 2017 The Authors. This is an open access article under the terms of the Creative Commons Attribution-NonCommercialNoDerivs License, which permits use and distribution in any medium, provided the original work is properly cited, the use is non-commercial and no modifications or adaptations are made. 
intensive care units suffered from anxiety (5). Anxiety may affect the ability of family members to receive and understand information, maintain adequate working patterns in the family, employ effective coping skills, and provide positive support for the patient (9). Therefore, it is necessary to make use of support and strategies to prevent and reduce anxiety producing factors (10). In various studies, the need for information, support, and hope have been reported as the basic needs of family members (11). Moreover, studies have indicated that developing caring programs focusing on the needs of the patient and family is an important factor in reducing the anxiety of the patient and family. Such training programs, in addition to reducing anxiety, will enable the family to provide more support to their patient (12). Many studies have been conducted relating to the effect of education on the anxiety of families with a patient hospitalized in an intensive care unit; however, there are different results. These contradictions bring about ambiguities regarding the effect of training role on controlling anxiety. Hence, it seems necessary to resolve this contradiction using different methods of research. One such method could be metaanalysis, which is the combining of results of studies to present a comprehensive picture of the care given. Therefore, this study aimed at determining the effect of education on the anxiety level of the families with patients in the critical care unit using meta-analysis.

\section{Material and Methods}

\subsection{Search Strategy}

To find the electronically published studies up to 2016, articles published in journals indexed in the following databases were used: Web of Science, science, Elsevier, Scopus, ProQuest, ISI, Springer, PubMed, Google scholar, Cochrane. The keywords used for searching the articles were family anxiety, ICU and education, with the operators "or" and "and" in the title and the abstract. All searches were limited to "English Language". To increase the sensitivity, lists of the references of the articles were checked. Search was conducted by two independent persons and the agreement between the search results of these two was controlled by a third person. The search time was 15th of March 2015 to 16th of April 2016.

\subsection{Study Selection}

Full text or abstracts of all papers, documents and reports were extracted from the Advanced Search. After removing duplicates, the irrelevant articles were also excluded by controlling the title, abstract and full text of the articles. It should be noted that to prevent bias caused by reprint (transverse and longitudinal publication bias), survey findings to identify and remove duplicate research have been considered in the research agenda.

\subsection{Quality Assessment}

After determining the relevant studies in terms of titles and content, two authors evaluated the quality of the included trials. In order to assess the quality of documentation, the JADAD scale was used. The JADAD scale is a 5 point scale for measuring the quality of randomized trials. A score of three points or more, indicates high quality $(13,14)$. The JADAD scale describes the order of random trial $(0=$ no description, $1=$ inadequate description, $2=$ adequate description); how the blinding is carried out $(2=$ double-blinding with adequate description, $1=$ doubleblinding with inadequate description, $0=$ wrong usage of double-blinding), Why and how the patients were excluded from the study (when the numbers and reasons of exclusion were reported as 1 or otherwise, 0 ). Two reviewers independently assessed the quality of the studies. In cases of disagreement, further consultation of the third-party comments was used.

\subsection{Data Extraction}

In each of the initial studies, data were extracted based on the title, the name of the first author, year of publication, names of countries, the sample size in the intervention and control groups, the random allocation, blinding status, number of withdrawal, the mean score of anxiety and the standard deviation in the intervention and control groups.

\subsection{Inclusion Criteria Studies}

All studies that earned the required score after the evaluation process were included in the study. They were evaluated based on type of training intervention, the population of the patients' families, type of anxiety outcome, type of interventional study, sample size, whether they had reported the median, mean and standard deviation of anxiety scores in the intervention and control groups, as well as the studies that had used State-Trait Anxiety Inventory questionnaire. 


\subsection{Exclusion criteria Studies}

Some studies have to be excluded because they have not reported average anxiety scores and standard deviations in the intervention and control groups, or have not mentioned the sample size, their abstracts were presented in congresses and conferences without any full text, or they couldn't achieve a minimum score of quality assessment.

\subsection{Analysis}

Stata Software ver. 11 was used for data analysis. The heterogeneity index between studies was determined, using Cochran $(\mathrm{Q})$ and I-squared $\left(\mathrm{I}^{2}\right)$. Due to the heterogeneity, random effects model was used to estimate the difference between the standardized mean of anxiety. Estimates of standardized difference points in mean score of anxiety were calculated with $95 \%$ confidence interval accumulation graph (forest plots). In this graph, the square size chart represents the weight of each study and the line in both sides show $95 \%$ confidence interval. The Egger test was also conducted to assess the publication bias, and significant level of less than 0.01 was considered for judgment criteria.

\section{Results}

The initial search through the information databases helped us find 27,149 articles, among which, 25,277 were excluded after we limited the search strategy. Characteristics of early studies entered the meta-analysis are shown in Table 1. From the 1,872 remaining articles, 320 were excluded because of overlapping databases. The titles and abstracts of 1,552 articles were checked, and so, 1,500 articles were removed because they were irrelevant. In the next step, 52 articles were selected and the whole article was reviewed; it was found that 40 of them were not related to our study. At this time, while checking the references, two other articles were found. Therefore, we came up with 14 articles that were checked using Jaded quality assessment checklist. Finally, 7 more articles were excluded due to the checklist and 7 articles entered the systematic review process and meta-analysis (Figure 1).

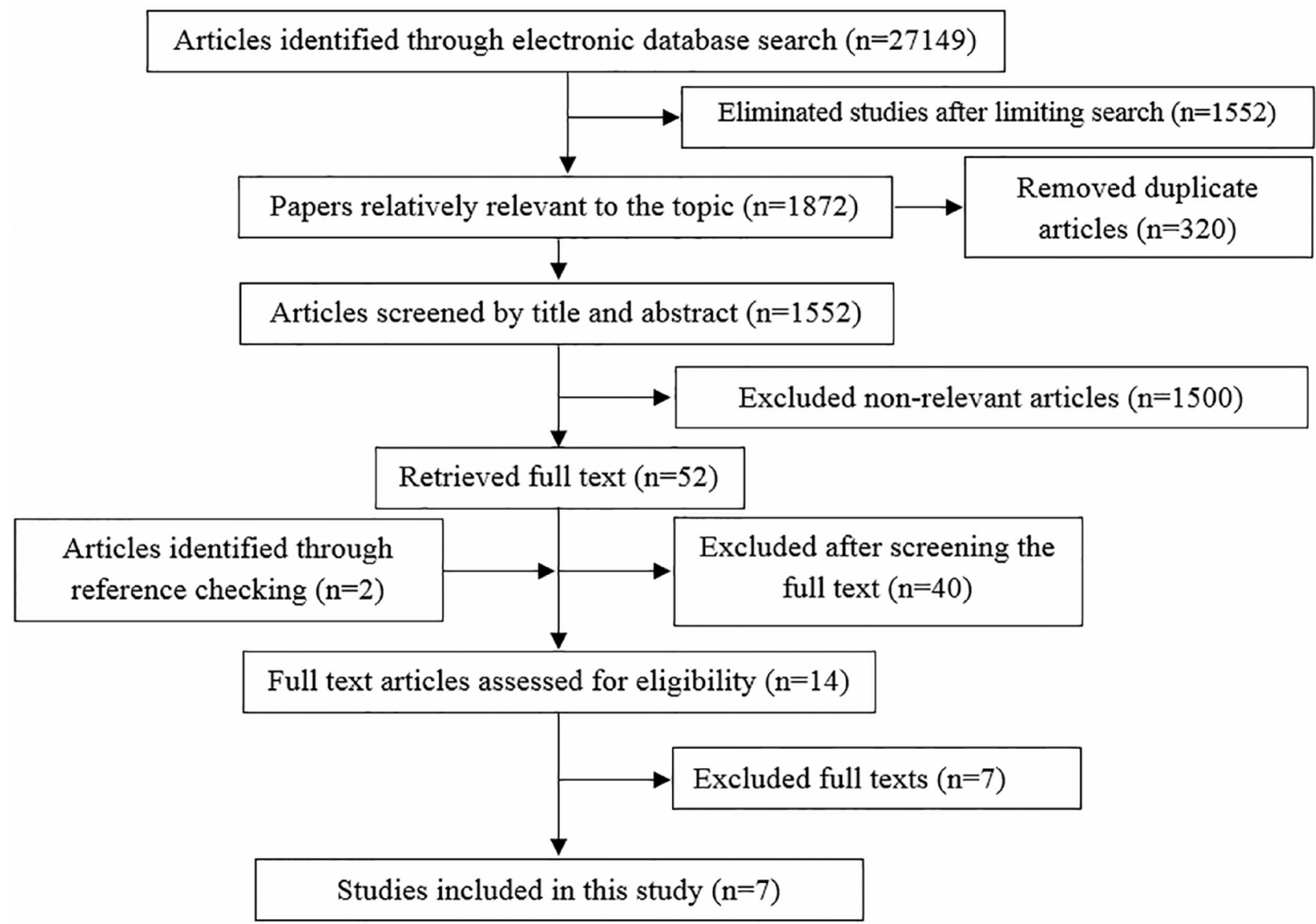

Figure 1. Literature search and review flowchart for selection of primary studies.

Seven studies had worked on the effect of training on average anxiety scores of patients' families. The number of samples in the initial studies was 387 participants in the intervention group and 393 in the control group. Except for 
one study that had reported just the median, the other 7 articles reported mean and the standard deviation, and so, entered the meta-analysis. The results of 7 studies were integrated using meta-analysis with a high heterogeneity level between studies (I-squared $=86.3 \%, \mathrm{Q}=43.9, \mathrm{p}<0.001$ ). According to the random effect model, the standardized difference between the mean score of anxiety in the intervention group (CI 95\%: -0.756-0.099)-0.329 units was less than that of the control group. However, this effect was not statistically significant (Figure 2). The Egger test used to assess publication bias showed that there was also no significant publication bias, $(\beta=-1.65, \mathrm{p}=$ $0.908)$. To investigate the factors suspected to heterogeneity, year of publication $(\beta=0.07, p=0.747)$ as a variable was entered in the Meta-regression model, and it was statistically demonstrated that it didn't have a significant role in the creation of heterogeneity.

Table 1. Characteristics of early studies entered the meta-analysis

\begin{tabular}{|l|l|l|l|l|l|l|l|l|}
\hline \multirow{2}{*}{ Ref. no. } & Questionnaire & Sample size & \multicolumn{2}{l|}{ Interventional } & \multicolumn{2}{l|}{ Control } & \multirow{2}{*}{ p-value } \\
\cline { 3 - 8 } & & Interventional & Control & Mean & SD & Mean & SD & \\
\hline 15 & STAI* & 32 & 32 & 31.4 & 6.9 & 7.2 & 7.2 & 0.18 \\
\hline 17 & STAI & 46 & 48 & 43.23 & 4.49 & 5.41 & 5.41 & 0.176 \\
\hline 18 & STAI & 34 & 32 & 39.93 & 7.23 & 6.53 & 6.53 & 0.006 \\
\hline 19 & STAI & 82 & 80 & 37.72 & 13.92 & 13.45 & 13.45 & 0.05 \\
\hline 20 & STAI & 45 & 45 & 42.97 & 4.59 & 6.76 & 6.76 & 0.743 \\
\hline 21 & STAI & 22 & 22 & 40.54 & 15.11 & 12.37 & 12.37 & 0.05 \\
\hline 22 & STAI & 78 & 82 & 40.42 & 11.65 & 15.26 & 15.26 & 0.001 \\
\hline
\end{tabular}

*STAI: State-Trait Anxiety Inventory

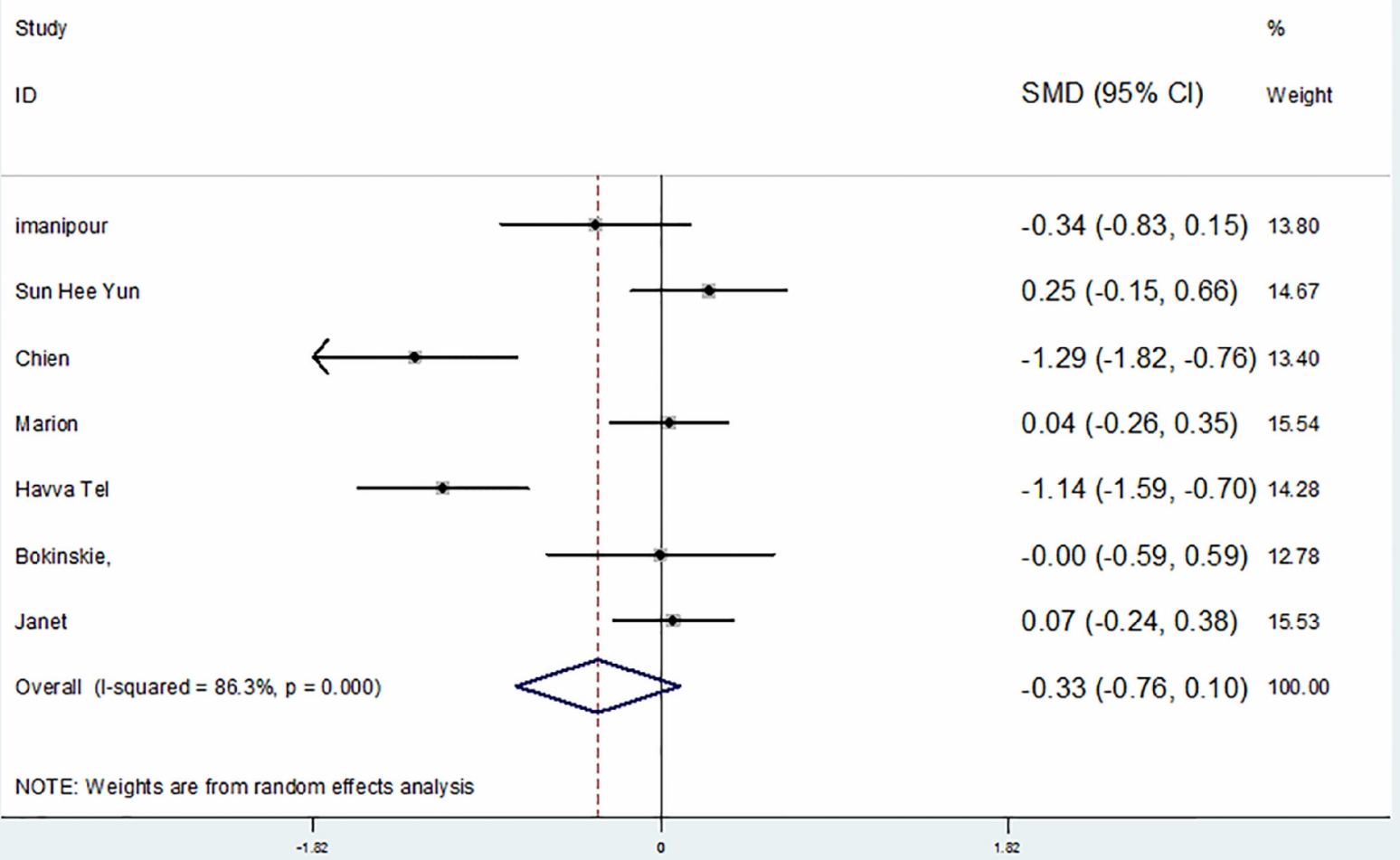

Figure 2. Average difference in anxiety between intervention and control groups with $95 \%$ of confidence for each of the preliminary and overall assessment.

\section{Discussion}

In this meta-analysis and systematic review, the effect of education on the level of anxiety in families of patients in a critical care unit was determined. The results of this meta-analysis have shown that education has reduced the anxiety level in families with patients in intensive care units, though this reduction was not statistically significant. 
In a study by Chien et al., need-based training reduced the anxiety score of families with ICU patients from 58.23 to 48.81 during and after the intervention (18). In the study conducted by Tel, et al., it was demonstrated that the anxiety score of families in the intervention group was less than that of the control group when transferring patients from ICU (42.97 vs. 49.57) (20). However, the study carried out by Janet, et al., indicated that providing information and writing a diary of patients, could decrease the level of family anxiety in the intervention group from 45.18 to 40.42 which was quite similar to the control group that showed a decrease in anxiety level from 46.52 to 39.53 , revealing that providing information could not reduce their anxiety level (22). Another study by Yan et al. showed that training families with neurologically hospitalized patients in ICU through focus groups and interviews, could reduce their anxiety to some extent, but this reduction was not statistically significant (17). One of the reasons for insignificance of anxiety reduction in this study can be due to the existence of less anxiety in the control group in comparison to the intervention group before the study. This situation is likely because random assignment is not carried out in an appropriate manner. In a study by Chien et al., training plans based on family needs, could significantly reduce anxiety because the training program has been continued and also the families were contacted through telephone at least once in a day and were informed about the condition of their patient (18). Thus, not maintaining continuous communication with the family in the other studies can be one of the reasons why the results were not statistically significant in this meta-analysis. It seems that having phone calls with the patient's family can be effective in enhancing and understanding the training. In addition, families' questions can be answered through telephone (23). Thus, providing families with continuous training seems necessary. One of the duties of nurses, is providing support for families and helping them to cope with the crisis. This should be done through contact with the family and informing them about the clinical course and the patient's health status (24). On the other hand, the nature of the disease affects the amount of anxiety in the family and the kind of support they need. Simply having good knowledge about various aspects of the disease, treatment and care cannot be helpful for the family in coping with the current situation per se. It is clear that various factors affect the family, coping with the crisis. Similar to the nature of the disease and its spectrum, which can range from mild to severe, duration of illness, the effect of illness on the family, financial losses caused by the disease, the effect of disease on the future performance of the family, accurate and on time notification of the family when their loved one is in critical condition can help provide an appropriate health care system (25). Guidelines in the health care centers of ICU patients in the USA (26) and the National Institute for Health and Rehabilitation in the United Kingdom (27) support the patients' families by providing adequate information during the critical period of the illness. In the United States, providing information is performed in various ways, such as spoken, written, and video instructions by a member of the health care team. In the United Kingdom, evidence-based written information tailored to the patients' needs is recommended. Both guidelines demonstrate the obligation to provide adequate information for both patients and family. It seems that developing caring programs focused on the needs of the patient and family is an important factor in reducing the anxiety of the patients and their families. Such supporting programs, in addition to reducing anxiety, will enable the family to provide more support to their patient (12). One of the limitations of this meta-analysis was the heterogeneity between the initial studies, though such factors were not identified. However, the probable factors can be the random allocation of sampling and conditions attributed to evaluate outcomes in the intervention and control groups. Nevertheless, due to the heterogeneity, the random effects model was used to estimate.

\section{Conclusions}

The results of this meta-analysis showed that training has decreased the anxiety level in families with patients hospitalized in intensive care units, although it was not considerable. This review highlights the need for further research with carefully planned RCTs exploring systematically the impact of the following variables: length of stay in an ICU, the setting of the intensive care (territory, community and academic center), the relationship of the family members to the patient, and if this is the patients' first admission to an intensive care setting. Our work provides evidence that appropriate interventions can reduce family members' anxiety. We recommend all ICU departments to provide appropriate written and oral information to longitudinal patients hospitalized.

\section{Acknowledgments:}

We acknowledge the support provided from the Mazandaran University of Medical Sciences with the allocation of the authors time.

\section{Conflict of Interest:}

There is no conflict of interest to be declared. 


\section{Authors' contributions:}

All authors contributed to this project and article equally. All authors read and approved the final manuscript.

\section{References:}

1) Clemen-Stone S, McGuire SL, Eigsti DG. Comprehensive community health nursing: Aggregate and Community Practice. 6th ed. Mosby: St Louis, MO; 2002.

2) Du Gas BW. Introduction to patient care: a comprehensive approach to nursing: WB Saunders Company; 1983.

3) Pourmemari M, Khaleghdoost Mohammadi T, Askandari F, Avazeh A. Study on effective factors on patients' family members anxiety in intensive care units. ZUMS. 2010; 18(70): 91-101.

4) Bephage G. Social and Behavioural Sciences for Nurses: An Integrated Approach: Elsevier Health Sciences; 2000.

5) Pochard F, Azoulay E, Chevret S, Lemaire F, Hubert P, Canoui P, et al. Symptoms of anxiety and depression in family members of intensive care unit patients: ethical hypothesis regarding decision-making capacity. Crit Care Med. 2001; 29(10): 1893-7. doi: 10.1097/00003246-200110000-00007. PMID: 11588447.

6) Elizarrarás-Rivas J, Vargas-Mendoza JE, Mayoral-García M, Matadamas-Zarate C, Elizarrarás-Cruz A, Taylor M, et al. Psychological response of family members of patients hospitalised for influenza A/H1N1 in Oaxaca, Mexico. BMC psychiatry. 2010; 10(1): 104. doi: 10.1186/1471-244X-10-104. PMID: 21129214, PMCID: PMC3016311.

7) Bunzel B, Roethy W, Znoj H, Laederach - Hofmann K. Psychological consequences of life - saving cardiac surgery in patients and partners: measurement of emotional stress by the Impact of Event Scale. Stress Health. 2008; 24(5): 351-63. doi: 10.1002/smi.1194.

8) Anderson WG, Arnold RM, Angus DC, Bryce CL. Posttraumatic stress and complicated grief in family members of patients in the intensive care unit. J Gen Intern Med. 2008; 23(11): 1871-6. doi: 10.1007/s1 1606-008-0770-2. PMID: 18780129, PMCID: PMC2585673.

9) Leske JS. Interventions to decrease family anxiety. Crit Care Nurse. 2002; 22(6): 61-5. PMID: 12518569.

10) Stewart M, Choate K. Reducing anxiety in patients and families discharged from ICU. Aust Nurs J. 2002; 10(5): 29. PMID: 12503383.

11) Trimm DR, Sanford JT. The process of family waiting during surgery. J Fam Nurs. 2010; 16(4): 435-61. doi: 10.1177/1074840710385691. PMID: 21051758.

12) Levey RE, Dieter RA, Preston JC, Smith PM, Levey TL, editors. Psychological needs of coronary artery bypass surgery patients. 2nd Virtual Congress of Cardiology; 2001.

13) Jadad AR, Moore RA, Carroll D, Jenkinson C, Reynolds DJM, Gavaghan DJ, et al. Assessing the quality of reports of randomized clinical trials: is blinding necessary? Controlled clinical trials. 1996; 17(1): 1-12. PMID: 8721797.

14) Li J, Liu Z, Chen R, Hu D, Li W, Li X, et al. The quality of reports of randomized clinical trials on traditional Chinese medicine treatments: a systematic review of articles indexed in the China National Knowledge Infrastructure database from 2005 to 2012. BMC Complement Altern Med. 2014; 14(1): 1. doi: 10.1186/1472-6882-14-362. PMID: 25256890, PMCID: PMC4192762.

15) Imanipour M, Heidari Z, Seyedfatemi N, Haghani H. Effectiveness of Informational Support on Anxiety among Family Carers of Patients Undergone Open Heart Surgery. Hayat. 2012; 18(3): 33-43.

16) Chaboyer W, Thalib L, Alcorn K, Foster M. The effect of an ICU liaison nurse on patients and family's anxiety prior to transfer to the ward: an intervention study. Intensive Crit Care Nurs. 2007; 23(6): 362-9. doi: 10.1016/j.iccn.2007.04.005. PMID: 17681470.

17) Yun SH, Oh EG, Yoo YS, Kim SS, Jang YS. Development and Effects of a Transition Nursing Program for Patients and Family Caregivers at a Neurological ICU in Korea. Clin Nurs Res. 2017: 26(1): 27-46. doi: 10.1177/1054773815616973. PMID: 26655563.

18) Chien WT, Chiu Y, Lam LW, Ip WY. Effects of a needs-based education programme for family carers with a relative in an intensive care unit: a quasi-experimental study. Int J Nurs Stud. 2006; 43(1): 39-50. doi: 10.1016/j.ijnurstu.2005.01.006. PMID: 16183062.

19) Mitchell ML, Courtney M. Reducing family members' anxiety and uncertainty in illness around transfer from intensive care: an intervention study. Intensive Crit Care Nurs. 2004; 20(4): 223-31. doi: 10.1016/j.iccn.2004.05.008. PMID: 15288876. 
20) Tel H, Tel H. The effect of individualized education on the transfer anxiety of patients with myocardial infarction and their families. Heart Lung. 2006; 35(2): 101-7. doi: 10.1016/j.hrtlng.2005.09.001. PMID: 16543038.

21) Bokinskie JC. Family conferences: a method to diminish transfer anxiety. J Neurosci Nurs. 1992; 24(3): 129-33. PMID: 1645034.

22) Kloos JA, Daly BJ. Effect of a Family - Maintained Progress Journal on Anxiety of Families of Critically Ill Patients. Crit Care Nurs Q. 2008; 31(2): 96-107. doi: 10.1097/01.CNQ.0000314469.41507.cb. PMID: 18360139.

23) Kucia A, Quinn T. Acute Cardiac Care: A Practical Guide for Nurses: Wiley \& Sons; 2013.

24) Kozier B. Fundamentals of nursing: concepts, process and practice. Pearson Education; 2008.

25) Bournes DA, Mitchell GJ. Waiting: the experience of persons in a critical care waiting room. Res Nurs Health. 2002; 25(1): 58-67. doi: 10.1002/nur.10019. PMID: 11807920.

26) Davidson JE, Powers K, Hedayat KM, Tieszen M, Kon AA, Shepard E, et al. Clinical practice guidelines for support of the family in the patient-centered intensive care unit: American College of Critical Care Medicine Task Force 2004-2005. Crit care med. 2007; 35(2): 605-22. doi: 10.1097/01.CCM.0000254067.14607.EB. PMID: 17205007.

27) National Institute for Health and Clinical Excellence. Rehabilitation after critical care (online) www.nice.org.uk/nicemedia/live/12137/43526/43526.pdf. 